\title{
Implementasi Algorithma Dijkstra Dalam Pencarian Rute Terpendek Fasilitas Kesehatan Tingkat I (Studi Kasus BPJS Kesehatan Kota Bengkulu)
}

\author{
Ardi Wijaya ${ }^{1}$, Edo Kurniawan ${ }^{2}$ \\ Program Studi Teknik Informatika Fakultas Teknik Universitas Muhammadiyah Bengkulu Jln.Bali (Telp. (0736) 22027, 22765 Fax. \\ (0736) 26161; e-mail: penulis1@institusi.ac.id)_ardiwijaya@umb.ac.id, ${ }^{2}$ Edo_kurniawan@gmail.com
}

\begin{abstract}
Faskes or in English is Health facilities are the firstlevel health facilities and become the first place for society to get treatments or medicines. If this first Health Facilities are not able viewed in the context of human resources or medical equipment, the patients will be recommended to send to a further health facility. According to Munir (2010: 4), that the Djikstra algorithm is named based on the inventor's name namely Djikstra Edsger. The Djikstra algorithm applied the greedy principle, where in every step was selected a side with a minimum weight that connected to a chosen node to another node that has not been selected yet. Web application afford to assign the shortest route until it can facilitate users in searching for health facilities at the close-in distance. This application employed Google Maps to display health facilities location data, routes to destinations, and others. This application hopefully performs frequent data update so as this application can follow GIS technology development.

Keywords: Health facilities, Djikstra, Website, Maps
\end{abstract}

Intisari-Faskes adalah singkatan dari fasilitas kesehatan, sedangkan 1 adalah tingkat pertama, jadi faskes 1 artinya fasilitas kesehatan tingkat pertama dan menjadi tempat pertama yang harus didatangi peserta jika ingin berobat, apabila Faskes 1 tidak sanggup baik dari segi sumber daya manusia maupun peralatan medis maka peserta akan dirujuk ke faskes lanjutan. Algoritma Djikstra dinamai sesuai dengan nama penemunya yaitu Edsger Djikstra. Algoritma Djikstra menggunakan prinsip greedy, dimana pada setiap langkah dipilih sisi dengan bobot minimum yang menghubungkan sebuah simpul yang sudah terpilih dengan simpul lain yang belum terpilih [1]. Aplikasi $W e b$ yang dapat menentukan rute terpendek sehingga dapat memudahkan pengguna dalam melakukan pencarian fasilitas kesehatan dengan jarak terdekat. Aplikasi ini menggunakan Google Maps untuk menampilkan data lokasi fasilitas kesehatan, menampilkan rute ke tujuan, dan lainnya. Untuk menggunakan Google Maps pada aplikasi ini. Diharapkan aplikasi ini selalu melakukan update data sehingga aplikasi ini mengikuti perkembangan teknologi $G I S$

Kata Kunci : Faskes, Djikstra, Website, Maps

\section{PENDAHULUAN}

Dengan perkembangan teknologi informasi, peta tidak berupa lagi lembaran ataupun buku. Saat ini terdapat layanan peta secara digital yang sudah ditanamkan pada perangkat bergerak. Kelebihan dari peta ini adalah memudahkan pengguna dalam mencari lokasi suatu tempat. Algoritma Djikstra dinamai sesuai dengan nama penemunya yaitu Edsger Djikstra. Algoritma Djikstra menggunakan prinsip greedy, dimana pada setiap langkah dipilih sisi dengan bobot minimum yang menghubungkan sebuah simpul yang sudah terpilih dengan simpul lain yang belum terpilih [1].

Faskes adalah singkatan dari fasilitas kesehatan, sedangkan 1 adalah tingkat pertama, jadi faskes 1 artinya fasilitas kesehatan tingkat pertama dan menjadi tempat pertama yang harus didatangi peserta jika ingin berobat, apabila Faskes 1 tidak sanggup baik dari segi sumber daya manusia maupun peralatan medis maka peserta akan dirujuk ke faskes lanjutan.

Setiap orang dalam melakukan perjalanan pasti memilih rute terpendek untuk mencapai tujuannya, karena dapat menghemat waktu dan tenaga, dalam aplikasi yang dibangun tersebut nantinya akan ditanamkan algoritma yang berfungsi sebagai pencari rute terpendek lokasi fasilitas kesehatan tingkat 1 , dan algoritma yang digunakan adalah algoritma Djikstra, algoritma ini akan membandingkan bobot terkecil dari node awal sampai ke node tujuan untuk menemukan jalur paling efisien.

Penerapan algoritma Djikstra merupakan salah satu langkah atau cara untuk membantu dalam menentukan pencarian rute manakah yang terdekat dengan lingkungan tempat tinggal calon anggota BPJS kesehatan, untuk mempermudah menentukan Fasilitas Kesehatan Tingkat 1 (satu).

$$
\text { Untuk mengatasi permasalahan ini }
$$
maka diperlukan suatu aplikasi Web yang dapat menentukan rute terpendek sehingga dapat memudahkan 
pengguna dalam melakukan pencarian fasilitas kesehatan dengan jarak terdekat.

\section{Tinjauan Pustaka}

Sistem pengolahan data berkembang sangat cepat seiring dengan pesatnya perkembangan teknologi komputer. Salah satu sistem pengolahan data yang sangat popular di beberapa negara maju, khususnya dalam bidang survei dan pemetaan adalah Sistem Informasi Geografis (SIG) [2].

\section{A. Sistem Informasi Geografis}

Pada dasarnya, istilah Sistem Informasi Geografis (SIG) merupakan gabungan dari tiga unsur pokok yaitu sistem, informasi dan geografis. Dengan melihat unsur- unsur tersebut, maka jelas SIG merupakan salah satu sistem informasi yang menekankan pada unsur "informasi geografis". SIG terdiri dari data spasial dan aspasial [3].

B. Peta

Peta merupakan penyajian grafis dari permukaan bumi dalam skala tertentu dan digambarkan pada bidang datar melalui sistem proyeksi peta denganmenggunakan simbolsimbol tertentu sebagai perwakilan dari objek- objek spasial di permukaan bumi. Peta mengandung arti komunikasi, artinya peta merupakan suatu alat penyampaian sinyal atau saluran informasi antara si pengirim pesan (pembuat peta) dan si penerima pesan (pemakai peta) [4].

Agar komunikasi tersebut berjalan lancar maka sebuah peta harus memiliki syarat-syarat sebagai berikut:

1. Peta tidak boleh membingungkan, dalam hal ini peta perlu dilengkapi ketarangan/legenda, skala, judul peta, bagian dunia mana.

2. Peta harus dapat dimengerti atau ditangkap maknanya oleh sipemakai peta supaya mudah dimengerti atau ditangkap maknanya, dan yang perlu digunakan ialah tata warna, symbol, dan system proyeksi dan system kordinat.

3. Pada harus memberikan gambaran yang sebenarnya tingkat ketelitian harus disesuaikan dengan tujuan dan jenis peta, serta kesanggupan skala peta itu dalam menyatakan ketelitian.

\section{Basis Data}

Basis data merupakan kumpulan dari data yang saling berhubungan satu dengan yang lainnya, tersimpan diperangkat keras komputer dan digunakan perangkat lunak untuk memanipulasinya. Penerapan basis data (database) dalam sistem informasi disebut juga dengan database system [5].

\section{Pencarian Rute Terpendek}

Lintasan terpendek adalah jarak yang ditempuh dari suatu titik ke titik yang lain dengan jarak tempuh yang paling pendek. Untuk mencari lintasan terpendek dalam suatu graph, berarti membicarakan masalah optimasi. Graph yang digunakan dalam mencari lintsan terpendek, menggunakan graph berbobot. Bobot pada graph bisa berupa jarak, waktu, biaya dan sebagainya. Biasanya, bobot yang ada pada graph berupa nilai positif. Tetapi tidak menutup kemungkinan terdapat nilai yang negatif [6]. Ada beberapa istilah yang berhubungan dengan graph, antara lain:

1. Vertex

Vertex adalah himpunan node/titik pada sebuah graf

2. Edge

Edge adalah himpunan garis yang menghubungkan tiap node/vertex

3. Graf berarah dan tidak berbobot: tiap busur mempunyai anak panah yang tidak berbobot.

Graf tidak berarah dan tidak berbobot: tiap busur tidak mempunyai anak panah dan tidak berbobot

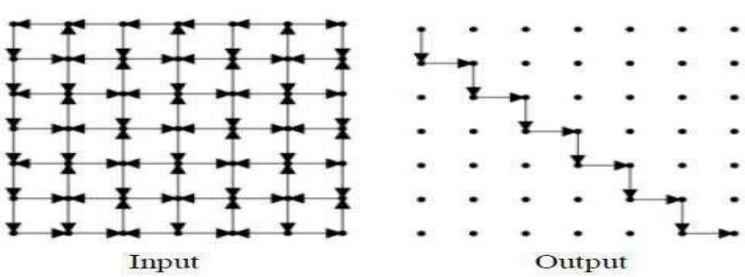

Gambar 1. . Contoh Pencarian Rute Terpendek

\section{III.METODOLOGI PENELITIAN}

Metodologi pengembangan sistem menggunakan pendekatan Rapid Application Development (RAD) 
yang menekankan pada siklus pembangunan pendek, singkat, dan cepat [7]. Waktu yang singkat adalah batasan yang penting untuk model ini. RAD menggunakan metode iteratif (berulang) dalam mengembangkan sistem dimana working model (model bekerja) sistem dikonstruksikan di awal tahap pengembangan dengan tujuan menetapkan kebutuhan (requirement) user dan selanjutnya disingkirkan.Berikut ini adalah gambaran kerangka pemikiran dari Rapid Aplication Development (RAD), dapat dilihat pada Gambar 1.

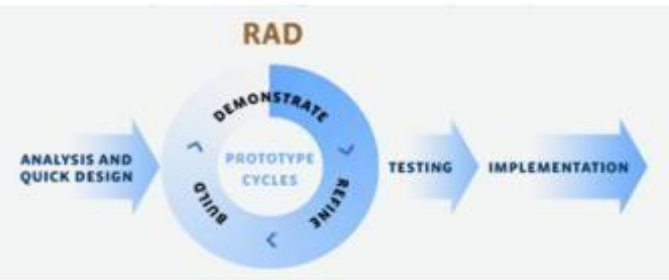

Gambar 1. Kerangka Kerja RAD

A. Analysis And Quick Design

1. Tahapan Pengumpulan data

a) Observasi

Dalam hal ini observasi dilakukan secara formal maupun informal untuk mengamati secara kualitatif berbagai kegiatan yang terjadi. Dalam penelitian ini perlu dilakukan observasi untuk memperoleh informasi yang lebih spesifik tentang alamat fasilitas kesehatan tingkat I pada BPJS Provinsi Bengkulu dan pengambilan data koordinat lokasi fasilitas kesehatan tingkat I menggunakan software pada playstore yaitu latitude longitude location.

b) Wawancara

Wawancara dilakukan kepada pihak BPJS Provinsi Bengkulu sebagai pusat data.

c) Studi Pustaka

Studi Pustaka yaitu pengumpulan data yang besumber dari arsip/dokumen yang terdapat pada BPJS Provinsi Bengkulu, selain itu juga menggunakan data yang bersumber dari buku kepustakaan, hasil penelitian dan arsip/dokumen yang berhubungan dengan penelitian ini.

2. Penjelasan Hardware dan Software

Sistem ini akan dibangun berbasis web sehingga penjelasan hardware dan software dirasa cukup penting demi kelancaran dalam proses membangun sistem ini. Adapun spefikasi hardware yang diperlukan dalam membangun sistem ini adalah minimal laptob atau Personal Komputer dengan kemampuan processor intel core i3 ditunjang dengan RAM minimal 2GB serta media penyimpanan HDD 500GB. Adapun Software yang digunakan dalam membangun sistem ini adalah, 1. Sistem Operasi berupa Windows 7 ,

2. Aplikasi berupa Dreamweaver dan XAMPP.

\section{B. Prototype Cycles}

1. Rancangan File

Digram koteks pada gambar 3.2 di bawah ini menggambarkan tentang proses kerja sistem ini secara umum. Admin dapat melakukan input data wilayah, input data faskes, data peserta dan data admin pada sistem informasi geografis, Sedangkan peserta dapat menerima informasi peta lokasi faskes terdekat.

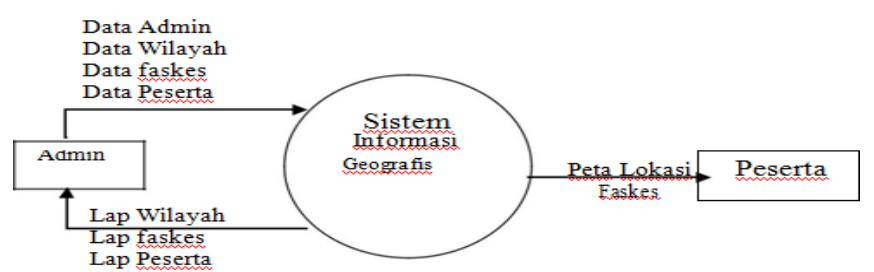

Gambar 2. Diagram Konteks

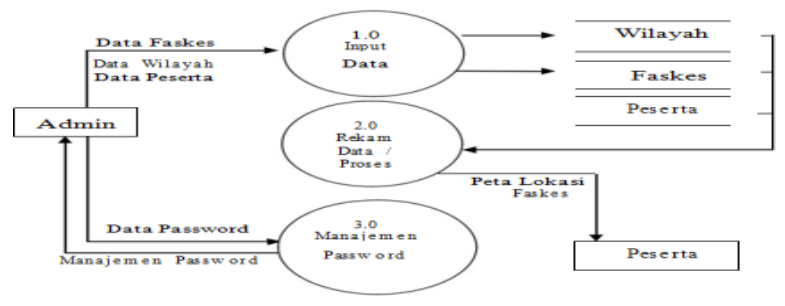

Gambar 3. Diagram Alir Data Level

2. Rancangan Interface

a. Rancangan Menu Awal 
Menu Awal ini adalah menu utama yang akan kita jumpai ketika pertama kali menggunak sistem ini.

\begin{tabular}{|c|}
\hline Tempat \\
Login \\
Content Index \\
\hline Footer \\
\hline
\end{tabular}

Gambar 4. Form Rancangan Menu Awal

b. Rancangan Peta Fasilitas Kesehatan Pada rancangan fasilitas kesehatan merupakan tampilan peta fasilitas kesehatan dan akan ditampilkan pada peta maps.

\begin{tabular}{|c|c|}
\hline Tempat & Login \\
\hline Content Peta & Data Lokasi \\
& \\
& \\
\hline
\end{tabular}

Gambar 5. Form Peta Fasilitas Kesehatan

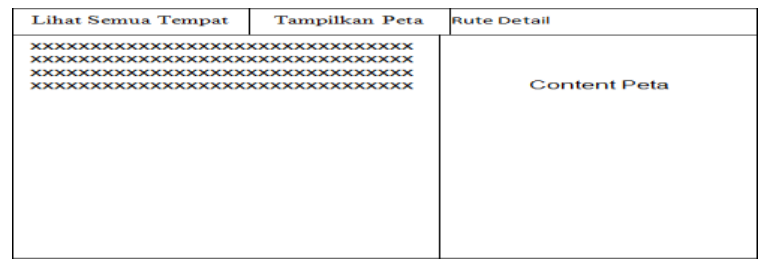

Gambar.6. Form Rancangan Jalur Terpendek

Setelah proses tahapan dari rancangan file dan rancangan interface selesai, maka tahapan yang akan selanjutnya dilakukan adalah tahapan program. Tahapan ini merupakan proses pengkodean rancangan kedalam sistem yang akan dibangun.

\section{Testing}

Setelah tahapan pengkodingan sistem selesai dilakukan, maka tahapan selanjutnya adalah menguji sistem ini dengan mengaplikasikannya langsung kepada beberapa pengguna, alat pengukurnya berupa penilaian kuisoner terhadap pengguna yang menggunakan sistem ini. Jika dirasa nilai dan tingkat kepuasan terhadap sistem ini cukup, maka sistem ini siap untuk di implementasikan.

D. Implementasi

Setelah semua proses rangkaian ini selesai dilakukan maka tahapan selanjutnya adalah implementasi sistem.

\section{IV.HASIL DAN PEMBAHASAN}

\section{A. Hasil}

Aplikasi Pencarian Rute Terpendek Untuk Menentukan Fasilitas Kesehatan Tingkat 1. Aplikasi ini mempunyai dua jenis halaman, yaitu halaman utama yang bersifat umum untuk pengunjung dan halaman admin yang digunakan administrator untuk mengelola data. Adapun gambaran awal dari graf faskes tingkat I adalah sebagai berikut :

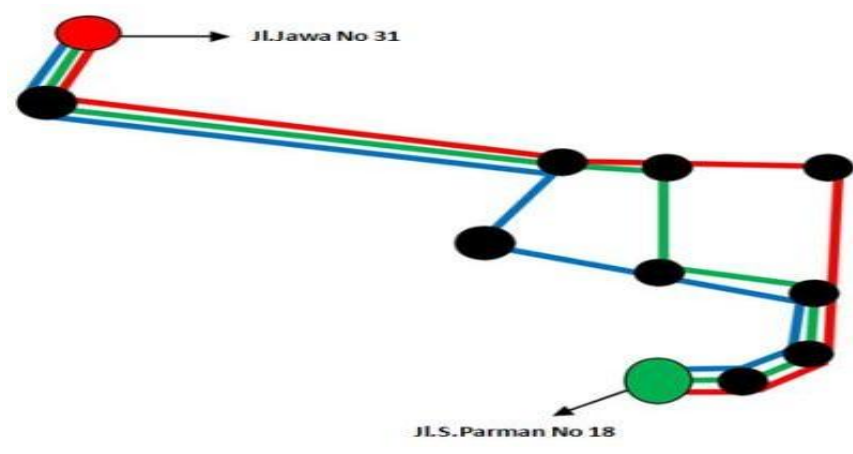

Gambar 7. Rute 1

Adapun daftar urut graf berdasarkan Jl.S Parman No 18, ke Jl. Jawa No 31 berdasarkan graf adalah sebagai berikut :

1. Menentukan objek faskes dengan koordinat sebagai berikut:
a. PKM Sukamerindu (-

3.7882791, 102.267327).

2. Menentukan graf berdasarkan koordinat objek faskes. Jadi untuk menghitung rute dari Jl.S Parman No 18 ke Jl. Jawa No 31 adalah sebagai berikut :

Dalam penentuan graf, setiap node memiliki satuan meter. Jadi setiap node akan mencari satuan meter yang terpendek.

a. Penentuan Ruas Pertama 


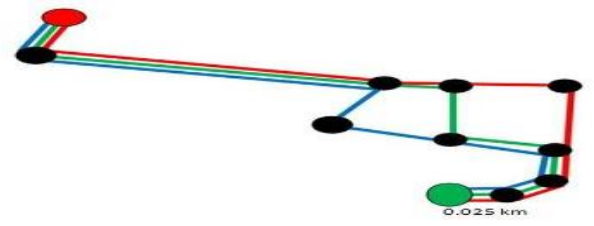

Gambar 8. Rute 2

b. Penentuan Ruas Kedua

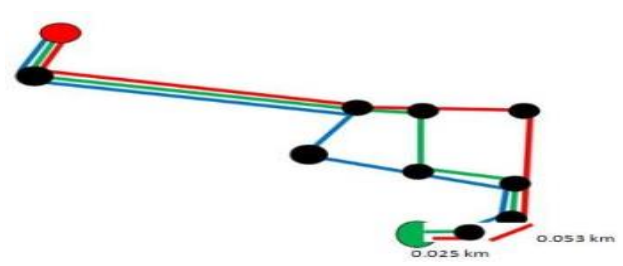

Gambar 9. Rute 3

c. Penentuan Ruas Ketiga

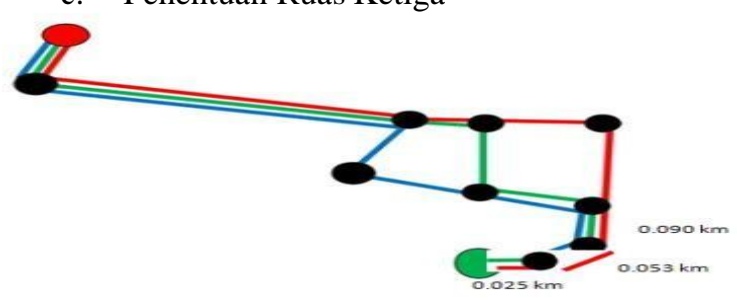

Gambar 10. Rute 4

d. Penetuan Ruas Keempat

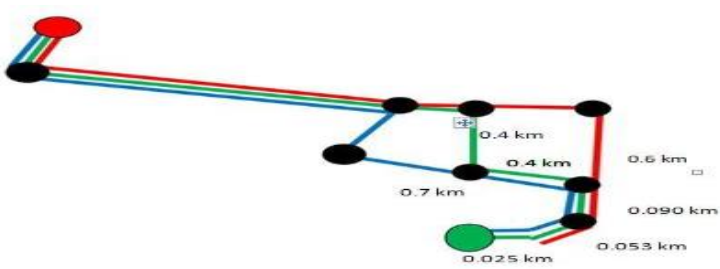

Gambar 10. Rute 5

e. Penentuan Ruas Kelima

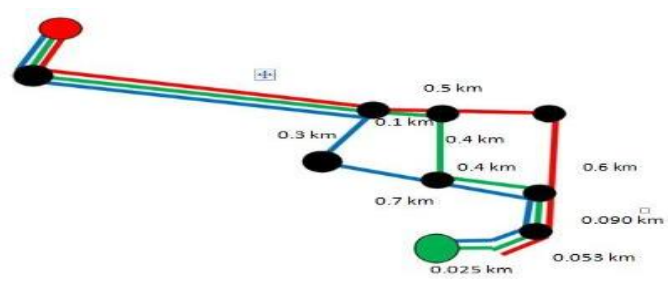

Gambar 10. Rute 6

f. Penentuan Ruas Keenam

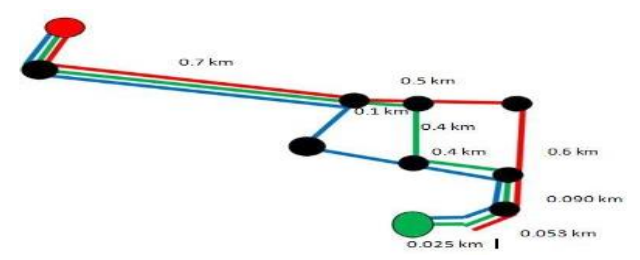

Gambar 10. Rute 7 f. Penentuan Ruas Ketujuh

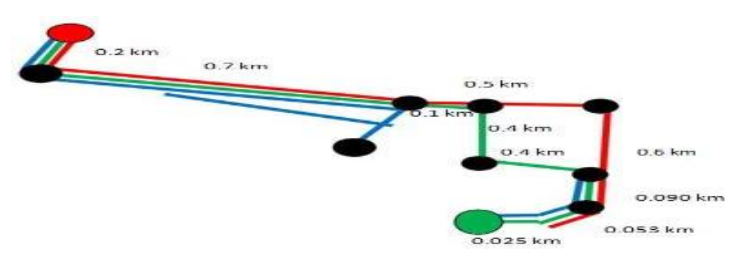

Gambar 10. Rute 8

Jadi untuk menghitung rute dari Jl.S Parman No 18 ke J1. Jawa No31 adalah sebagai berikut:

a. Titik Hijau ke titik merah alternatif 1 (jalur merah) $=0.025+0.053+0.090+0.6+0.5+0.7+0.2=$

b. $2.017 \mathrm{Km}$.

c. Titik Hijau ke titik merah alternatif 2 (jalur hijau $)=0.025+0.053+0.090+0.4+0.4+0.1+0.7+0$

i. $.2=2.006 \mathrm{Km}$

d. Titik Hijau ke titik merah alternatif 3 (jalur biru)

$0.025+0.053+0.090+0.7+0.3+0.7+0.2=$

$$
\text { i. } 2.026 \mathrm{Km}
$$

Jadi rute terbaik adalah rute pilihan alternatif yang ke dua (b), yaitu dengan jarak 2,006 Km.

\section{B. Pengujian Sistem}

Pengujian sistem dilakukan setelah Aplikasi Implementasi Algoritma Dijkstra Dalam Pencarian Rute Terpendek Untuk Menentukan Fasilitas Kesehatan Tingkat 1 yang dibuat telah selesai. Pengujian Kuisoner yang dilakukan bertujuan menambah nilai siklus hidup pengembangan perangkat lunak karena memungkinkan pelanggan sebenarnya kesempatan untuk memberikan masukan ke dalam desain, fungsi, dan kegunaan dari produk. Masukan ini tidak hanya penting untuk keberhasilan produk tetapi juga investasi ke produk masa depan ketika data yang dikumpulkan dikelola secara efektif.

Table 1 Pengujian Beta 


\begin{tabular}{|c|c|c|c|c|}
\hline \multirow{2}{*}{ No } & \multirow{2}{*}{ Kriteria } & \multicolumn{3}{|c|}{ Persentase \% } \\
\hline & & SM & $\mathrm{M}$ & TM \\
\hline 1 & Program bersifat Interaktif dan Dinamis & 15 & 4 & 1 \\
\hline 2 & Aplikasi membantu info lokasi faskes tingkat I & 16 & 4 & 0 \\
\hline 3 & $\begin{array}{l}\text { Digunakan sebagai media teknologi info lokasi } \\
\text { faskes tingkat I di Kota Bengkulu dengan } \\
\text { algoritma Djikstra }\end{array}$ & 5 & 14 & 1 \\
\hline 4 & Warna tampilan menarik & 5 & 10 & 5 \\
\hline 5 & Menu tampilan bersifat user friendly & 6 & 13 & 1 \\
\hline & Jumlah Responden & \multicolumn{3}{|c|}{20} \\
\hline
\end{tabular}

Keterangan :

1. Jumlah Pernyataan :

- Sangat Menarik = 47 Pernyataan

-Menarik = 45 Pernyataan

-Tidak Menarik $=8$ Pernyataan

Total = 100 pernyataan

2. Jumlah Responden : 20 Responden

Maka diperoleh jawaban sangat menarik $47 \%$, menarik $45 \%$, dan tidak menarik $8 \%$. Adapun cara perhitungannya adalah sebagai berikut :

1. Hitung setiap row pernyataan kemudian pernyataan dijumlahkan.

2. Lakukan perhitungan
a. Sangat menarik $=47 \%$
b. Menarik $=45 \%$
c. Tidak Menarik $=8 \%$

Hasil rincian dari perhitungan di atas dapat dilihat pada gambar 11 di bawah ini:

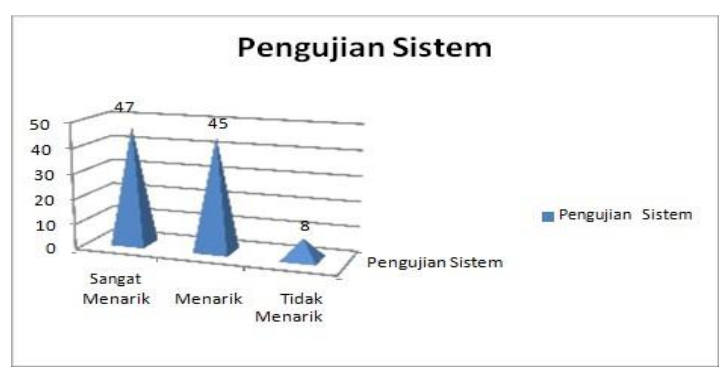

Gambar 11. Persentase Hasil Pengujian Sistem

\section{PENUTUP}

\section{A. Kesimpulan}

Berdasarkan hasil pembahasan dan pengujian dapat diambil kesimpulan sebagai berikut :
1. Menghasilkan aplikasi berbasis web yang dapat menentukan rute terpendek.

2. Mengimplementasikan algoritma Djikstra agar dapat menentukan rute terpendek.

3. Membantu kantor BPJS kesehatan dengan mudah dan cepat dalam pencarian fasilitas kesehatan tingkat 1 manakah yang paling terdekat di lingkungan tempat tinggal peserta BPJS kesehatan.

\section{B. Saran}

Dari kesimpulan diatas, ada beberapa saran agar dapat menggunakan program aplikasi ini dengan maksimal

1. Aplikasi ini selalu melakukan update data sehingga aplikasi ini mengikuti perkembangan teknologi GIS.

2. Aplikasi ini dapat dikembangkan pada kasus lainnya sehingga dapat menambah wawasan pada pemograman PHP dan MAP

\section{DAftar Pustaka}

[1] Munir, R., Matematika Diskrit, 4, 413-414, Informatika, Bandung, 2010

[2] KHARISTIANI, Erna; ARIBOWO, Eko. Sistem Informasi Geografis Pemetaan Potensi SMA/SMK Berbasis Web (Studi Kasus: Kabupaten Kebumen). Jurnal Sarjana Teknik Informatika, 2013, 2.1: 41-49.

[3] Prahasta, Eddy, 2002, Konsep-Konsep dasar Sistem Informasi Geografis, Informatika, Bandung.

[4] Riyanto, Putra, P. E., \& Inderlako, H. (2009). Pengembangan Aplikasi Sistem Informasi Geografis Berbasis Desktop dan Web. Yogyakarta: Gava Media.

[5] Jogiyanto, 2005, Pengenalan Komputer, Andi, Yogyakarta

[6] Yusuf, M. S., Az-Zahra, H. M., \& Apriyanti, D. H. (2017). Implementasi Algoritma Djikstra Dalam Menemukan Jarak Terdekat Dari Lokasi Pengguna Ke Tanaman Yang Di Tuju Berbasis Android. Jurnal Pengembangan Teknologi Informasi dan Ilmu Komputer, 1779-1787.

[7] Pressman, R. S. (2005). Software engineering: a practitioner's approach. Palgrave Macmillan 